
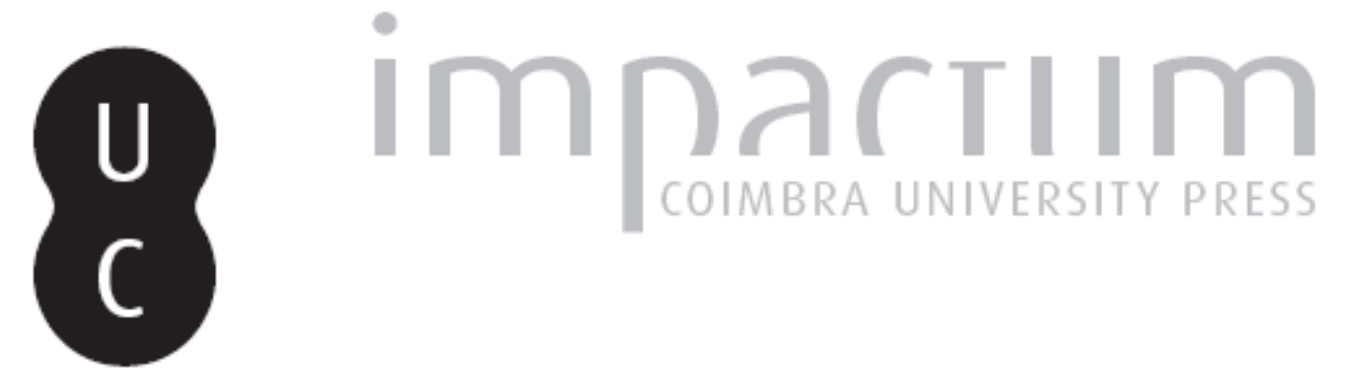

\title{
A rejeição da filosofia política em Isaac Abravanel
}

\section{Autor(es): Abranches, André}

Publicado por: Imprensa da Universidade de Coimbra

URL persistente:

URI:http://hdl.handle.net/10316.2/42846

DOI:

DOI:http://dx.doi.org/10.14195/0872-0851_50_1

Accessed : $\quad$ 26-Apr-2023 15:59:12

A navegação consulta e descarregamento dos títulos inseridos nas Bibliotecas Digitais UC Digitalis, UC Pombalina e UC Impactum, pressupõem a aceitação plena e sem reservas dos Termos e Condições de Uso destas Bibliotecas Digitais, disponíveis em https://digitalis.uc.pt/pt-pt/termos.

Conforme exposto nos referidos Termos e Condições de Uso, o descarregamento de títulos de acesso restrito requer uma licença válida de autorização devendo o utilizador aceder ao(s) documento(s) a partir de um endereço de IP da instituição detentora da supramencionada licença.

Ao utilizador é apenas permitido o descarregamento para uso pessoal, pelo que o emprego do(s) título(s) descarregado(s) para outro fim, designadamente comercial, carece de autorização do respetivo autor ou editor da obra.

Na medida em que todas as obras da UC Digitalis se encontram protegidas pelo Código do Direito de Autor e Direitos Conexos e demais legislação aplicável, toda a cópia, parcial ou total, deste documento, nos casos em que é legalmente admitida, deverá conter ou fazer-se acompanhar por este aviso.

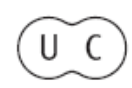




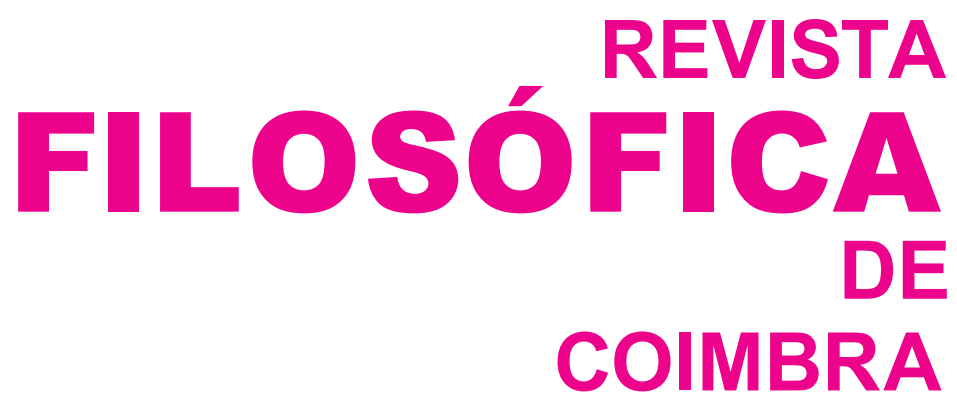

vol. 25 - número 50 - outubro 2016

vol. 25 - número 50 - outubro 2016

Fundação Eng. António de Almeida

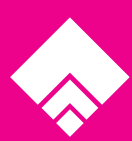




\title{
A REJEIÇÃO DA FILOSOFIA POLÍTICA EM ISAAC ABRAVANEL
}

\author{
THE REJECTION OF POLITICAL PHILOSOPHY
}

BY ISAAC ABRAVANEL

ANDRÉ ABRANCHES*

Resumo: Para Isaac Abravanel (1437-1508), a questão da rejeição da filosofia política está contida na questão mais específica da rejeição condicional da filosofia racionalista do judaísmo medieval. Na época do pensador português, que corresponde sensivelmente ao fim do período medieval e começo do Humanismo, essa filosofia era ortodoxia. Assumia a piedosa tarefa de defender a lei judaica. A rejeição operada por Abravanel assume-se como a rejeição condicional da filosofia racionalista enquanto defesa da Lei. Como a negação, em nome da verdadeira ortodoxia, dessa filosofia enquanto defesa legítima da ortodoxia judaica. Foi com o propósito de compreender por que é que o nosso autor rejeita a filosofia política, um assunto na verdade útil para aprofundar as clássicas questões da defesa e crítica da filosofia, que me debrucei sobre a sua obra.

Palavras-chave: Isaac Abravanel, Moisés Maimónides, Al-Farabi, São Tomás de Aquino, Platão, Aristóteles, Filosofia Política, Ciência Política, Revelação Divina, Lei.

Summary: For Isaac Abravanel (1437-1508), the subject of the rejection of political philosophy is contained in the more specific subject of the conditional rejection of medieval Judaism's rationalist philosophy. At the time of the Portuguese thinker, which corresponds to the late medieval Era and beginning of Humanism, this philosophy was or-
Résumé: Pour Isaac Abravanel (1437-1508), le sujet du rejet de la philosophie politique se retrouve dans le sujet plus spécifique du rejet conditionnel de la philosophie racionaliste du judaïsme médiéval. À l'époque du penseur portugais, qui correspond à la fin du Moyen Âge et au début de l'Humanisme, cette philosophie représentait l'orthodoxie.

* Doutor em filosofia política (Universidade Nova de Lisboa e University of Chicago); abranches.a@gmail.com 
thodoxy. It took upon itself the pious task of defending the Jewish law. The rejection operated by Abravanel asserts itself as the conditional rejection of rationalist philosophy as a form of defense of the Law. It is a denial, on behalf of the true orthodoxy, of this philosophy as legitimate defense of Jewish orthodoxy. In order to understand why Abravanel rejects political philosophy, a subject that turned out to be useful to deepen the classical questions of the defense and criticism of philosophy, I thus turned my attention to his work.

Keywords: Isaac Abravanel, Moses Maimonides, Al-Farabi, St. Thomas Aquinas, Plato, Aristotle, Political Philosophy, Political Science, Divine Revelation, Law.
Abravanel a pris sur lui-même la mission de défendre la loi juive, raison pour laquelle le rejet opéré par Abravanel s'affirme comme un rejet conditionnel de la philosophie racionaliste pour défendre cette loi - comme une légitime défense de l'orthodoxie juive. Afin de comprendre les raisons qui soutiennent de rejet de Abravanel pour la philosophie politique, j'ai procédé à l'analyse de son oeuvre, exercice utile pour approfondir les questions classiques de la défense de la philosophie et de sa critique.

Mots-clés: Isaac Abravanel, Moïse Maïmonide, Al-Farabi, saint Thomas d'Aquin, Platon, Aristote, la Philosophie Politique, la Science Politique, la Révélation Divine, la Loi.

Isaac Abravanel considera Moisés Maimónides (1135-1204) a maior figura da filosofia racionalista do judaísmo medieval. ${ }^{1}$ Para compreender a sua crítica à filosofia racionalista é recomendável começar por expor a forma geral da filosofia política do próprio Maimónides. Isso pede algumas considerações preliminares sobre a tradição filosófica do pensador judeu, tendo especial atenção à sua proximidade à tradição filosófica dos falãsifa - os filósofos islâmicos que ingressavam na (ou aprofundavam a) actividade filosófica através da tradução e estudo dos textos filosóficos gregos clássicos. $^{2}$

A tentativa de conciliar duas tradições, uma religiosa, por um lado, e $a$ tradição filosófica, por outro, era um exercício comum no período medieval.

1 Cf. Isaac Abravanel, Principles of Faith [Rosh 'Amanah], (Toronto: Ramat Gan, 1982), cap. 10. Como boas biografias de Isaac Abravanel: Erwin Rosenthal, "Don Isaac Abravanel, Financier, Stateman and Scholar", Bulletin of John Rylands Library, vol. 21, $\mathrm{n}^{\circ} 2$ (1937); Roland Goetschel, Isaac Abravanel, Conseiller des Princes et Philosophie, (Paris: Albain Michel, 1996).

2 Moses Maimonides, Treatise on Logic, (Jerusalem: Literary Licensing Reprint, 2001), cap. XIV. 
Foi cabalmente realizado no mundo islâmico por Al-Farabi (872-950), no judaico pelo próprio Maimónides e no cristão por São Tomás de Aquino (1225-1274) - apenas para dar alguns exemplos mais conhecidos. ${ }^{3}$ Para o pensador cristão, por exemplo, Aristóteles (384-322 a.C.) é a maior autoridade filosófica em todos os domínios do saber. É $o$ filósofo. Para os outros dois, por seu turno, Aristóteles é a maior autoridade filosófica em todos os domínios à excepção do saber político, pódio que reservam para o seu mestre - Platão (428-348 a.C.). São Tomás de Aquino procurava conciliar a tradição cristã com a tradição aristotélica, ao passo que o filósofo islâmico e o filósofo judeu pretendiam conciliar a sua respectiva tradição religiosa, por um lado, tanto com filosofia aristotélica como com a filosofia política platónica, por outro.

A natureza do islamismo e do judaísmo, quando comparada à do cristianismo, ajuda a explicar parte desta discrepância. No islamismo, tal como no judaísmo, a revelação divina assume-se como lei. ${ }^{4}$ No cristianismo, por contraste, assume-se como fé. Posto que, para o cristianismo, a revelação divina exige fé e não outra coisa, no seu exercício de conciliação o pensador cristão vê-se desde logo forçado a justificar, não a necessidade de filosofia, mas do "conhecimento revelado por Deus". ${ }^{5}$ De modo inverso, como para islamismo e para o judaísmo a revelação divina é lei, tanto Al-Farabi como Maimónides procuram justificar, não a lei ou revelação divina, mas a própria necessidade de filosofia. A urgência dessa justificação é tanto maior quanto maior for a impressão de que o filósofo é um descrente. ${ }^{6} \mathrm{Al}$-Gazhali (1058-1111), famoso teólogo e jurista islâmico, acérrimo defensor da lei divina, dá contas dessa suspeita generalizada que recai sobre os filósofos ao assinalar que "a fonte da sua descrença estava em darem ouvidos a nomes tão sonantes como a Sócrates, Hipócrates, Platão, Aristóteles e outros" e não apenas e exclusivamente à Sharia. ${ }^{7}$ No mundo medieval islâmico, ou no judaico, certos pensamentos podem ser encarados como uma forma de desobediência visto terem implícito o questionamento da lei.

Se nestes mundos a revelação divina exige a obediência incondicional à lei, a justificação da necessidade de filosofia tem de ser encontrada no terreno

3 Considere-se, por exemplo, Al-Farabi, Attainment of Happiness, §63, in: Philosophy of Plato and Aristotle, (Ithaca: Cornell University Press, 2001), Veja-se ainda Moses Maimonides, prefácio de Guide of the Perplexed, (Chicago: University of Chicago Press, 1963).

4 Considere-se Menachem Kellner, "Heresy and the Nature of Faith in Medieval Jewish Philosophy”, The Jewish Quarterly Review, vol. 77, no 4 (1987), 299 e ss.

5 Cf. Thomas Aquinas, Su.Theol. (S.L: Benziger Bros. Edition, 1947), I, 1.

${ }^{6}$ Acerca do facto de o filósofo apenas ser verdadeiramente leal à razão, o que passa pelo questionamento das coisas "geralmente aceites", veja-se Farabi, Philosophy of Plato, $\S 30$, in: Philosophy of Plato and Aristotle, (Ithaca: Cornell University Press, 2001).

7 Al-Gazhali, The Incoherence of the Philosophers, (Utah: Brigham Young University Press, 2000), cap. 4, 15-20 - (o itálico é nosso). 
da acusação de impiedade que the é dirigida. Para dizer a mesma coisa de outra maneira, se a revelação divina exige a obediência à lei, a filosofia não é uma forma de impiedade se consistir na demonstração de que a lei é perfeita, i.e., a lei característica do melhor regime político. A justificação da necessidade de filosofia assenta então na assunção de que a lei ou revelação divina pode ser (racionalmente) demonstrada enquanto lei perfeita e, por outro lado, de que o exercício demonstrativo per se não contraria o dever de obediência incondicional à revelação divina.

Para evitar a acusação de que a demonstração da perfeição da lei viola o princípio de obediência incondicional, os filósofos argumentam que a própria lei ou revelação divina habilita os homens capazes (e apenas eles), quer dizer, os potenciais filósofos, a fazer a referida demonstração. Por outro lado, ao afirmar que se trata de uma demonstração, os filósofos estão a admitir que a ideia da perfeição da lei pode ser apreendida pelo homem enquanto homem, isto é, tanto por crentes como por descrentes.

$\mathrm{O}$ argumento, porém, de que não faz mais que habilitar os potenciais filósofos ainda compromete a sua exigência de obediência incondicional. Permitir que não se demonstre que a lei é perfeita equivale a alienar a obediência voluntária dos descrentes. ${ }^{8}$ Neste sentido, os filósofos têm de argumentar que a própria lei obriga os potenciais filósofos a demonstrar a sua perfeição através de proposições acessíveis a todo e qualquer homem.

Como o filósofo, à semelhança do descrente, não reconhece gratuitamente a perfeição da lei, poderá ser dito que a revelação divina surge aos seus olhos como um facto político, como uma reivindicação política que concorre com as demais pelo título de melhor lei. ${ }^{9}$ Esta ideia leva a que os filósofos procedam a uma politização da revelação divina, passe a expressão, ou seja, à compreensão da Revelação Divina através da ciência das coisas políticas. Quis dizer, ao impor-se ao homem como $a$ autoridade, Lei ou reivindicação política par excellence, os potenciais filósofos são incitados a ingressar na investigação filosófica.

A lei obriga o filósofo a demonstrar a superioridade da lei, isto é, força a filosofia a apresentar-se como piedade. Por outro lado, impele o filósofo a iniciar-se no pensamento-livre, ou seja, a encarar a própria Lei como um conjunto de opiniões/crenças ou como um facto político. Se a primeira forma de coacção conduz à justificação política da filosofia, à justificação do filósofo na cidade, a segunda leva à filosófica, à justificação científica das

8 Cf. Maimonides, prefácio, Guide, - "A razão humana atraiu-o [homem religioso] a ficar dentro da sua esfera; e acha difícil aceitar como correcto o ensinamento baseado na interpretação literal da Lei, e especialmente aquilo que ele ou outros derivam daquelas expressões homónimas, metafóricas ou híbridas".

9 Veja-se Leo Strauss, "Some Remarks on Maimonides Political Science", Interpretation, vol. $18, \mathrm{n}^{\circ} 1$ (1990), 5 e 11. 
coisas. Se aquela, leal à Revelação Divina, conduz à preservação da piedade enquanto uma forma de obediência incondicional à lei, esta, leal à razão, conduz a uma investigação que está para além da piedade ou obediência. O exercício de conciliação de Al-Farabi e de Maimónides, mais que o de São Tomás de Aquino, encontra-se nesta perigosa tensão.

Atestar que a lei é a melhor lei, ou que a comunidade política fundada pelo profeta é o melhor regime político, é explicar a lei ou revelação divina em termos que sejam acessíveis à razão humana entregue a si mesma. Neste sentido, Maimónides tem de estabelecer um paralelo claro entre o discurso da revelação divina, e os seus recursos, por um lado, e o discurso filosófico, e os seus conceitos, por outro. ${ }^{10}$ Quer dizer, tem de estabelecer o paralelo, por exemplo, entre alguém como Moisés, proclamado profeta-fundador pela tradição judaica, e o rei-filósofo - sendo este um conceito desenvolvido, não por Aristóteles, mas por Platão. ${ }^{11}$ Noutros termos, quando a filosofia é naturalmente vista como uma actividade marginal, a filosofia política platónica permite apresentá-la como piedade. ${ }^{12}$

São essencialmente três tipos de opiniões características da obra de Platão que permitem a Maimónides, e na verdade a Al-Farabi, conciliar a filosofia com a lei. ${ }^{13}$

A primeira é a de que a lei baseia-se nas opiniões dos cidadãos da melhor das cidades. Essas opiniões, que possuem um carácter estritamente filosófico, funcionam como um prelúdio ou base da lei no seu todo, i.e., dos três diferentes tipos de opiniões autoritárias contidas na lei. Para descobrir as opiniões estritamente filosóficas, o filósofo é levado a imaginar ou a conceber a melhor das cidades. ${ }^{14}$

A segunda é a de que a lei baseia-se em "nobres mentiras": opiniões necessárias $e$ úteis à comunidade política que disfarçam a verdade. Para

10 Cf. Maimonides, prefácio, Guide.

11 Plato, Rep. 473C, in: The Collected Dialogues, (New Jersey: Princeton University Press, 1999). Considere-se ainda Farabi, Attainment, §40, §54, §57.

12 Será por esta razão que é tão importante para os filósofos (islâmicos e judeus) demonstrar que Platão e Aristóteles são harmonizáveis ou que têm uma e a mesma filosofia: Aristóteles só é defensável perante a Lei à luz dessa harmonização. Cf. Al-Farabi, The Harmonization of the Opinions of the Two Sages, §1, in: The Political Writings, (London: Cornell University Press, 2004); Farabi, Attainment, §63 e §64.

13 Excepcionalmente, ao encontro da tradição dos falãsifa vai um pensador cristão, Marsílio de Pádua, cujo aristotelismo diverge de São Tomás de Aquino e da tradição tomista. Considere-se, a título de exemplo, a divisão do seu Defensor Pacis em três tipos de discurso: Marsilius of Padua, Defensor Pacis, (New York: Columbia University, 2001), I, I, 8.

14 Cf. Platão, Rep. 568d-569b. Veja-se ainda Leis, livro V - discussão sobre as opiniões dos cidadãos da cidade excelente ou perfeita. 
descobri-las, o filósofo é levado a analisar em que medida a melhor das cidades, aquela simplesmente conforme à natureza, precisa de um certo tipo de opiniões falsas, i.e., um tipo de opiniões sem as quais nenhuma comunidade política subsiste. Digamos, o filósofo precisa de perceber até que ponto a cidade perfeita não pode ser simplesmente conforme à natureza, ou quais os seus limites. ${ }^{15}$

A terceira é a de que a lei baseia-se em opiniões estritamente necessárias. Opiniões não-filosóficas ou falsas, não propriamente úteis mas temporalmente precisas, que se tornam lei, e que como não podem ser demonstradas devem ser defendidas por argumentos persuasivos, ou seja, por uma arte especial - a arte da "defesa" ou "auxílio" da lei. ${ }^{16}$

Demonstrar que a lei (judaica) é perfeita equivale a demonstrar, entre outras coisas, que as suas crenças podem ser correctamente repartidas em função dos três tipos de opiniões pressupostos pela matriz platónica. Neste sentido, ao certificar, por hipótese, o carácter plenamente não-filosófico de certas crenças, o filósofo não está senão a afiançar que são necessárias, não por serem verdadeiras, mas por razões estritamente políticas. Quer dizer, a demonstração de que a lei judaica é perfeita contém o pressuposto, herético ou, no mínimo, dúbio, de que algumas crenças judaicas são falsas e poderão vir a ser descartadas.

A necessidade de apresentar a filosofia como piedade dita, porém, que para não cometer a heresia de afirmar algumas crenças ad usum, a demonstração filosófica tem de distinguir implicitamente as crenças verdadeiras das necessárias. Isto é, pressupõe a arte especial de apresentar as crenças necessárias de modo a que apenas os (muito poucos) potenciais filósofos, ao serem cautelosamente guiados pelo autor para detectarem alusões, contradições e argumentos retóricos deliberados, as consigam reconhecer como falsas e, ao mesmo tempo, distinguir dos demais tipos de crenças. ${ }^{17} \mathrm{~A}$ demonstração da perfeição da lei, tal como a própria lei, presta-se assim a dois tipos de interpretações. Uma radical, dirigida apenas aos muito poucos potenciais filóso-

15 Um exemplo desse tipo de opiniões/crenças seria o mito dos autóctones, ou a ideia de que um povo, o povo português, por exemplo, é naturalmente, e não por convenção, «português». Cf. Platão, Rep. 415d3-4. Veja-se ainda Cícero, De rep., II, 52, in: The Republic and The Laws, (Oxford: Oxford University Press, 2008).

16 Platão, Rep. 613a-614b. Sobre a arte especial considere-se Farabi, Philosophy of Plato, §36 e Enumeration, §5, in: The Political Writings, (London: Cornell University Press, 2004). Sobre a necessidade de os filósofos adoptarem e promoverem opiniões falsas considere-se Pádua, Defensor, I, V, 11.

17 Veja-se Farabi, Attainment, §41. Compare-se com Maimonides, prefácio, Guide, acerca do facto de que "nada está fora do sítio, cada observação procura ilustrar o assunto do respectivo capítulo. Não leia superficialmente, para que não me faça esse prejuízo e não se beneficie a si mesmo". 
fos que detectam a arte especial por detrás da defesa da lei, que distinguem as crenças verdadeiras das necessárias; outra literal, dirigida aos muitos não-filósofos, que apela ao seu zelo religioso enquanto aceitação incondicional e indiferenciada de todas as crenças. ${ }^{18}$

A obra de Maimónides e, em particular, o seu afamado Guia dos Perple$x o s$, que viria a constituir a maior referência do racionalismo medieval judeu, poderão inserir-se nesta tradição literária que remonta a Platão e encontra uma forte expressão em Al-Farabi. Com efeito, tem vindo a impor-se a tese de que Maimónides pretende fazer uma apresentação ortodoxa da perfeição da lei, ao mesmo tempo que deixa implícita uma hierarquização do carácter verdadeiro das crenças judaicas tradicionais.

Se o propósito de Maimónides for, entre outras coisas, conciliar a lei com a filosofia, como no judaísmo a creatio ex nihilo surge como a crença mãe, a crença da qual dependem as demais crenças judaicas tradicionais, esse exercício de conciliação enfrenta desde logo um sério obstáculo: $a$ tradição filosófica, e o próprio Aristóteles, defendem a sempiternidade do mundo visível. ${ }^{19}$ Por Moisés Maimónides ser obrigado a criticar a tese do filósofo grego, o que acaba por ser uma das funções centrais e explícitas do seu Guia, fica por saber se essa crítica corresponde ao seu próprio pensamento ou, ao invés, a uma combinação muito trabalhada entre um conjunto de opiniões geralmente aceites e opiniões verdadeiras.

A necessidade de analisar esta questão agrava-se com a observação, em particular, de que o próprio Guia acaba por pôr em causa a aceitação de várias crenças judaicas tradicionais dependentes da creatio ex nihilo sem que haja qualquer imposição (político-religiosa) para o fazer, o que sugere,

18 Rochelle Millen, “Isaac Abravanel's Concept of Monarchy”, An Interdisciplinary Journal of Jewish Studies, vol. 10, nº 9 (1992), 52 e ss.

19 Compare-se Maimonides, Guide, II, XV-XVI e III, 25 com Aristóteles, Phys. I, 7, 190b-3-5; VIII, 1. 251a, 8-20; Metaph. III, 4, 999b, 8, in: Complete Works, (New Jersey: Princeton University Press, 1991) com Platão, Tim. 37e6-38b5. Veja-se ainda Lawrence Kaplan, "Maimonides on the Miraculous Element in Prophecy", The Harvard Theological Review, vol. 70, no 3 e 4 (1977), 233 e ss. Não é razoável identificar o ensinamento do Timeu com o ensinamento cosmológico de Platão. Em todo o caso, poderá ser dito que o ensinamento de Timeu é o de que o universo (matéria) teve um início e não terá um fim. Aristóteles, por seu lado, defende que não teve um início nem terá um fim - cf. Seymour Feldman, "The End of the Universe in Medieval Jewish Philosophy", AJS Review, vol. 11, no 1 (1986), 68. É assinalado com frequência pelos comentadores de Maimónides que este pensador foi o primeiro a enunciar as crenças judaicas fundamentais. 
mutatis mutandis, que a crítica de Maimónides à tese platónica pode estar ao serviço da defesa da lei. Nasce assim o dever de examinar até que ponto a inconsistência de Maimónides não é deliberada, tanto para mais quando essas crenças ameaçadas pelo Guia são aprovadas pelo próprio pensador judeu nos seus Treze Artigos da Fé - uma obra destinada a compilar as crenças judaicas fundamentais. ${ }^{20}$

A impressão de que a conciliação operada por Maimónides obedece à matriz platónica agrava-se com a constatação de que o pensador judeu equaciona os fenómenos proféticos característicos da ciência da profecia enquanto englobantes dos próprios fenómenos políticos: a ciência da profecia contém a ciência política. ${ }^{21}$ Será por isso que no seu Tratado sobre a Lógica realça que três das quatro partes da ciência política, a saber, o governo da casa, o governo da cidade e o governo das grandes nações, são hoje resolvidos pelo Talmude, pelo que se dispensa as obras dos filósofos acerca destas matérias. Neste sentido, o messias e o profeta, os protagonistas das Sagradas Escrituras, juntam-se ao rei enquanto principais assuntos da ciência política. ${ }^{22}$

Particularizando, para o pensador judeu, o profeta-legislador, como Moisés, no encalço da República e das Leis de Platão, surge como um rei-filósofo capaz de transmitir a lei perfeita, eterna e imutável, e, em especial, de guiar Israel. ${ }^{23}$ Ao apoderar-se do conceito de rei-filósofo, Maimónides pode facilmente alinhar-se com a tradição exegética do judaísmo medieval que sustenta que lei mosaica prescreve univocamente a instituição monárquica. Por aparecer como o veículo através da qual a Lei chega aos homens, o rei não a pode violar senão em casos de flagrante urgência, sob custo de punições pelo Supremo Tribunal. ${ }^{24}$ Adicionalmente, o monarca tem a obrigação de impor a melhor das leis a todos os homens (crentes e descrentes), promover a justiça e assumir a liderança militar. Já o messias é $o$ rei-filósofo. Um rei profeta,

20 Compare-se Maimonides, Guide, III, XXIII, com Moses Maimonides, Thirteen Principles of Faith, (Leiden: 1974), XIII. Alguns autores, como Arthur Hyman, consideram que os Treze Artigos retêm uma validade definitiva para o próprio Maimónides, in: Alexander Altman, (Harvard: Harvard University Press, 1967), 2. Veja-se ainda Moses Maimonides, Book of Letters and Responsa, (Jerusalem: 1978), 9. De acordo com o próprio Maimónides, em 1189, no Iémen, um leitor do seu Guia enviou-lhe uma carta desagradado com o facto de Maimónides não ter elaborado a crença da ressurreição física dos mortos, o que então gerou uma grande controvérsia.

21 Compare-se Maimonides, Guide, II, 32 e ss. e III, 45, com Maimonides, Treatise, XIV. Cf. ainda Leo Strauss, Maimonides Statement on Political Science, in: What Is Political Philiosophy? and Other Studies, (Chicago: The University of Chicago Press, 1988).

22 De fora fica apenas o autogoverno do homem, ou seja, a Lei judaica não tornou obsoletas as obras gregas e árabes sobre a ética.

23 Cf. Maiminides, Guide, I, 54 e II, 39-40.

24 Cf. Ibid, III, 27-28. 
obediente à Lei, um líder militar bem-sucedido que resgata Israel da servidão a outros povos e deuses, que restaura o reino de David no país de Israel, estabelece a paz universal e cria a condição terrena ideal para uma vida dedicada ao conhecimento, i.e., à Lei.

Tendo por base uma matriz política platónica, passe a expressão, o protagonismo político do profeta e do messias reflecte o racionalismo de Moisés Maimónides. O Guia não apresenta o messias como autor de milagres, nem a era messiânica como o período que regista uma alteração no regular curso da natureza, viz., o fim do mundo visível. A crítica ou a correcção feita a estas crenças judaicas tradicionais não comprova que Maimónides rejeita a creatio ex nihilo - a criação do universo é compatível com a não-extinção do mundo visível -, mas pelo menos pressupõe que o carácter eterno do mundo visível não pode ser infirmado pela discussão da vinda do messias ou da era messiânica: o mundo visível existirá para sempre, o que contraria seguramente a interpretação judaica tradicional. ${ }^{25} \mathrm{~A}$ discussão dos fenómenos messiânicos corresponde por conseguinte mais a uma esperança racional, como aquela de Sócrates a propósito da escassa possibilidade de realizar o melhor regime político na terra, do que a uma crença supra-racional. Com a diferença decisiva de que, seguindo o exemplo de Al-Farabi, por contraposição ao próprio Platão, por Maimónides colocar uma tónica tão grande nas virtudes militares e na coragem, a sua esperança como que ainda menos dependente está do sopro favorável da fortuna (Tyche). Por esta razão, o racionalismo de Maimónides torna-se especialmente evidente com a inserção da ciência do messias na discussão temática dos "reis e as suas guerras" em Mishneh Torah (A Repetição da Torá). A arte militar é um dos factores decisivos na queda ou preservação dos Estados. Em particular, foi uma deficiência militar, uma negligência na arte da conquista e da guerra, que no passado levou à destruição do Estado judeu. Neste sentido, o messias, sendo um líder militar bem-sucedido, possui a virtude e a perícia militar indispensáveis à restauração do Estado de Israel: o destino do povo Judeu depende, não de milagres ou do destino, mas sobretudo da ciência e do mérito do homem.

\section{III}

Isaac Abravanel rejeita categoricamente a interpretação radical da demonstração da perfeição da lei judaica, o que também o leva a afastar a ideia do carácter dual das crenças da lei judaica. Quer dizer, assume a interpretação literal do Guia dos Perplexos como a única interpretação legítima dessa obra, o que pressupõe que corresponde ao pensamento de Maimónides,

25 Cf. Ibid, II, 29. 
e até como a única interpretação legítima da própria lei judaica. Abravanel vê-se como um defensor da lei judaica contra a tradição judaica que se foi firmando, comentário a comentário, sobre premissas filosóficas em tudo pelo menos heterodoxas. ${ }^{26}$

Ao proclamar-se lei, o judaísmo presta-se à conciliação com a tradição filosófica através da filosofia política platónica, que opera implicitamente a distinção entre crenças necessárias e verdadeiras para demonstrar a perfeição da Lei. Para recusar essa distinção, Abravanel procura anular o âmbito da própria filosofia (política) ao reforçar a apresentação do judaísmo, não tanto enquanto lei, mas sobretudo enquanto reportório de crenças, seguindo aliás as pisadas dos Treze Artigos da Fé e da própria Escolástica Cristã. ${ }^{27}$

Com efeito, o nosso autor aceita não só como verdadeira a doutrina da creatio ex nihilo do Guia, que defende em Sefer Shamayim Hadashim (Baseado nas questões da Eternidade e Criação do Guia dos Perplexos de Maimónides), bem como, nos seus Rosh 'Amanah (Princípios da Fé), as crenças tradicionais judaicas ameaçadas no Guia e defendidas nos Treze Artigos da $F_{e} .^{28}$ Procura tornar perfeitamente concordante/consistente o ensinamento literal do Guia e, assim, articular a defesa da crença judaica basilar com a defesa das restantes crenças judaicas fundamentais enunciadas na compilação das crenças feita por Maimónides. ${ }^{29}$ Subentendida à sua rejeição da interpretação radical do Guia e à distinção entre tipos de crenças, fica uma crítica absolutamente decisiva a toda e qualquer filosofia da lei divina, como

${ }^{26}$ Considere-se Eric Lawee, «Isaac Abarbanel's "Stance toward Tradition": The Case of “"Ateret zeqenim”», AJS Review, vol. 22, no 2 (1997), 165 e ss. e ainda Cedric Skalli, "Discovering Isaac Abravanel's Humanistic", The Jewish Quarterly Review, vol. 97, No 1 (2007), 67 e ss.

27 É aqui que se compreende a sua preferência por leituras cristãs da lei face a comentadores judeus e/ou islâmicos, por um lado, e a sua preferência por Aristóteles face a Platão. Cf. Isaac Abravanel, Commentary on Joshua, X, 12, f. 21, col. 2, in: Commentary on the Prophets, (Jerusalem: Torah ve-Daat, 1956).

28 Cf. Isaac Abravanel, Sefer Shamayim Hadashim, (Jerusalem: Roedelheim, 1966/67) e Abravanel, Rosh, cap. 22. Sobre Abravanel e a sua veia de comentador do Guia de Maimónides veja-se, Cedric Skalli, "Yitsh aq Abravanel's First Edition (Constantinople 1505) Retorical Content and Editorial Background", Hispania Judaica Buletin, The Mandel Institute of Jewish Studies, $\mathrm{n}^{\circ} 5$ (2007), 156 e ss. Sobre o propósito dos Rosh 'Amanah veja-se ibid., 159 e ss. Sobre a defesa que Abravanel faz a Maimónides contra comentadores islâmicos e judeus, veja-se Menachem Kellner, "Isaac Abravanel on the Principles of Judaism", Journal of the American Academy of Religion, vol. 45, no 4 (1977), 500 e ss. Por fim, sobre a crença na creatio ex nihilo de Abravanel veja-se Benzion Netahyahu, Don Isaac Abravanel: Statesman and Philosopher, (New York: Cornell University Press, 1998), 103 e ss.

29 Compare-se Maimónides, Thirteen, XII e XIII com Abravanel, Rosh, cap. 10 e 19. 
a platónica. O verdadeiro judeu só pode ser leal, por assim dizer, não à razão, mas à Mishná do Talmude. ${ }^{30} \mathrm{O}$ verdadeiro judeu, tal como o humanista, volta às raízes da Tradição, embora, ao contrário deste, elas sejam não as fontes clássicas do pensamento mas o sentido literal da Bíblia e o próprio Flávio Josefo.

A rejeição da interpretação radical do Guia feita pelo pensador português reúne várias tendências intelectuais diametralmente opostas às tendências da obra global de Maimónides, como certas configurações de anti-racionalismo, anti-platonismo, apolitismo e, por vezes, até, anti-politismo.

O anti-racionalismo de Abravanel está associado, grosso modo, ao seu anti-platonismo. A impossibilidade de conciliar a tradição filosófica essencialmente aristotélica, por um lado, e a tradição judaica, por outro, traduz-se no fundo na impossibilidade de demonstrar a perfeição da lei. ${ }^{31}$

O carácter anti-platónico da matriz anti-racionalista pressupõe uma certa forma de apolitismo. Ao se admitir que a perfeição da lei judaica não pode ser demonstrada negasse, assim, que a ciência da profecia engloba a ciência política. Neste sentido, Abravanel remove as temáticas do messias e do profeta do conjunto dos principais temas da ciência política. A cisão radical entre as duas ciências é preparada pela asserção de que a profecia não é um fenómeno natural, ou seja, de que a razão não a pode explicar na sua plenitude. ${ }^{32}$ Quer dizer, é sustentada pela asserção de que o profeta, tal como o messias, não é um rei-filósofo. ${ }^{33}$ Ao invés, as lideranças do profeta e do messias, bem como a profecia e o messianismo, são fenómenos fundamentalmente supranaturais e suprapolíticos. ${ }^{34}$

30 Sobre a rejeição da filosofia da lei divina considere-se Eugene Mihaly, "Isaac Abravanel on the Principles of Faith", Hebrew Union College Annual, vol. 26 (1955), 481.

31 Isso explica que, tal como São Tomás de Aquino, o pensador português preferira Aristóteles a Platão, i.e., uma discussão da política essencialmente fechada à questão do melhor regime político: cf. Abravanel, Genesis, X, 1, f. 40, col. 1, in: Commentary on the Pentaeuch, (Jerusalem: Benei Arabel, 1964). Veja-se ainda Avraham Melamed, "Isaac Abravanel and Aristotle's Politics: a Drama of Errors", Jewish Political Studies Review, vol. $5, \mathrm{n}^{\mathrm{o}} 3$ e 4 (1993), 55 .

32 Cf. Commentary on the Guide of the Perplexed, II, 32, in: Isaac Abravanel, Commentary on the Pentaeuch, (Jerusalem: Benei Arabel, 1964). E ainda Abravanel, I Kings, III, 14, f. 210, col. 4, in: Commentary on the Prophets, (Jerusalem: Torah ve-Daat, 1956). Compare-se com Maimonides, Guide, II, 32-34.

33 Cf. Abravanel, I Kings, III, 14, f. 211, col. 1.

34 Esta convicção, bem como a de que a vinda do messias estava próxima, é alimentada pelo facto de Abravanel ser contemporâneo de certos acontecimentos históricos: grandes revoluções na história da diáspora judaica e o fim período medieval e o começo da modernidade. 
Um reflexo particular dessas essências supranaturais e suprapolíticas é a Era messiânica, que é definida pela ocorrência de vários milagres, pela paz universal e não particularmente por nenhuma façanha político-militar; outro, é a Era pós-messiânica, que é anunciada por uma terrível guerra, pela guerra final, e que culmina no fim do mundo visível. ${ }^{35} \mathrm{Na}$ escatologia testemunha-se a impotência política e militar: não há nada que o político ou o militar possa fazer para impedir o seu destino, o da cidade e o do mundo. ${ }^{36}$ Condenada a desaparecer, o profeta e o messias pretendem, não a salvação da cidade, mas a redenção do homem.

O ensinamento político de Abravanel, onde discute as formas humanas de governo, como a monarquia, insere-se nesta linha anti-racionalista, que ao limite denota uma veia não só apolítica, mas também, como se aludiu acima, vincadamente antipolítica. Alguns comentadores de Abravanel entendem que essa tendência radica na crítica de Lúcio Séneca à civilização, em geral, e à cidade, em particular. ${ }^{37}$ Outros, por sinal, acrescentam que remonta igualmente aos ensinamentos acerca dos primeiros capítulos do Génesis tanto do judeu Flávio Josefo, como dos Padres Cristãos. ${ }^{38}$

O pensador português concebe as expressões mais acabadas da vida política - a vida urbana, o governo coercivo, a propriedade privada, etc. -, como subprodutos da rebelião do homem contra a ordem instituída por Deus: a única vida verdadeiramente conforme à ordem divina decorre do estado de liberdade e igualdade de todos os homens, vivida no campo e em famílias independentes. ${ }^{39}$ Séneca alude a uma ideia em tudo semelhante quando, ao citar Vergílio, assinala que nenhuma condição terrena merece tanta aprovação humana como aquela em que "nenhum colono arava a terra; assinalar limites aos campos e delimitar propriedades era crime, todos produziam para todos, e a própria terra oferecia, sem que alguém os reclamasse, livremente os seus frutos". ${ }^{40}$ Neste sentido, tal como estóico romano, a crítica do judeu português não visa substituir uma forma de organização política por outra, mas denunciar toda e qualquer forma de vida política enquanto expressões supérfluas e artificiais da vida humana. ${ }^{41}$

35 Considere-se Isaac Abravanel, The Deeds of God, (Veneza: 1592), cap. 8, e Feldman, 68 e ss.

36 Abravanel, Isaiah, XI e Judges, I, 19, in: Commentary on the Prophets, (Jerusalem: Torah ve-Daat, 1956).

37 Cf. J. F. Baer, "Don Jizchaq Abravanel”, Tarbiz, VIII (S.D.), 248-253.

38 Cf. James Loewe, Isaac Abravanel's Six Lectures, Cambridge University Press, 1937, 208.

39 Abravanel, Genesis, XI, 1 e ss.

40 Cf. Lúcio Séneca, Cartas a Lucílio, (Lisboa: Fundação Calouste Gulbenkian, Lisboa), LXXXIX, 37-38 e Virgil, Georgics, (New York: Bilingual Editions, 2006), I, 125-8.

41 Em todas as Cartas de Séneca abundam os exemplos da denúncia dos bens supérfluos e do elogio da verdadeira filosofia, à imagem do que acontece na obra de Epicuro. 
É neste ponto que do anti-racionalismo aflora a veia antipolítica de Isaac Abravanel. Como a vida conforme à ordem instituída por Deus corresponde à da Era Dourada - uma vida que se assemelha à agreste domilicium de Séneca -, e como essa vida possui um carácter milagroso, a vida política fica desprovida da possibilidade de elevar o homem às verdadeiras virtudes. ${ }^{42}$ A vida natural, digamos assim, assemelha-se ou é idêntica à vida no deserto, onde Israel teve de depender totalmente da providência milagrosa. ${ }^{43}$ Isto quer dizer que a vida vivida na Era Dourada não é menos dependente dos milagres que a da Era messiânica, na qual o carácter milagroso daquela é devidamente restaurado e na qual a vida política deve estar subsumida.

É o predomínio da crença na existência de milagres, e na faceta genuína de uma vida que é vigiada e orientada pela providência milagrosa que se substitui ao governo político humano auto-suficiente, que tornam o pensamento de Abravanel anti-racionalista e antipolítico. A este ponto já é possível constatar que, na classificação da ciência política, não podia haver maior contraste entre Abravanel e Maimónides. Se é verdade que Maimónides, seguindo as pisadas de Al-Farabi, aceita por completo a ideia aristotélica de

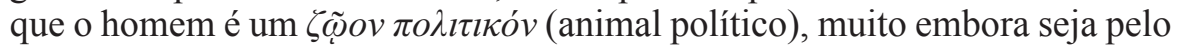
menos extremamente hesitante na aceitação da crença em milagres, também é verdade que Abravanel, que aceita sem quaisquer reservas a crença na existência de milagres, considera que a vida política, em geral, e a própria instituição monárquica, em particular, são coisas pecaminosas e relutantemente concedidas ao homem por Deus. ${ }^{44}$

Cf. ibid. LXXXIX, 38-46. Veja-se ainda Abravanel, Genesis, XI, 1 e ss., f. 41, col. 1-2. As filosofias de Séneca e de Abravanel contrastam fortemente com as de Platão e de Aristóteles, por estes entenderem, ao contrário daqueles, que só a cidade e os laços políticos quando devidamente orientados podem levar a que o homem se torne o mais perfeito possível.

42 Cf. Seneca, Cartas, LXXXIX, 42. Sobre o carácter milagroso da vida natural veja-se Abravanel, Joshua, X, 12, f. 21, col. 3.

43 Cf. Abravanel, Genesis, XI, 1 e ss., f. 41, col. 3 e Exodus, XVIII, 13-27, f. 134, col. 2, in: Commentary on the Pentaeuch, (Jerusalem: Benei Arabel, 1964).

44 Abravanel, Genesis, II, 18. Considere-se também Flavius Josephus, Antiquities of the Jews, (S.L: Veritatis Splendor Publications, 2014), XX, 10, 1. 


\section{Referências bibliográficas}

Abranches, André. O Caminho para a Verdadeira Ciência Política. Lisboa: RosenCrantz, 2014.

Abravanel, Isaac. Rosh 'Amanah. Toronto: Ramat Gan, 1982.

Abravanel, Isaac. Sefer Shamayim Hadashim. Jerusalem: Roedelheim, 1966/67.

Abravanel, Isaac. Commentary on the Prophets. Jerusalem: Torah ve-Daat, 1956.

Abravanel, Isaac. Commentary on the Pentaeuch. Jerusalem: Benei Arabel, 1964.

Abravanel, Isaac. The Deeds of God. (Veneza: 1592).

Al-Farabi. Philosophy of Plato and Aristotle. Ithaca: Cornell University Press, 2001.

Al-Farabi. The Political Writings. London: Cornell University Press, 2004.

Al-Gazhali. The Incoherence of the Philosophers. Utah: Brigham Young University Press, 2000.

Altman, Alexander. Jewish Medieval and Renaissance Studies. Harvard: Harvard University Press, 1967.

Aquinas, Thomas. Summa Theologica. S.L: Benziger Bros. Edition, 1947.

Aristotle. Complete Works. New Jersey: Princeton University Press, 1991.

Baer, J. F. "Don Jizchaq Abravanel”. Tarbiz: VIII.

Cicero. The Republic and The Laws. Oxford: Oxford University Press, 2008.

Feldman, Seymour. "The End of the Universe in Medieval Jewish Philosophy". AJS Review, vol. 11, nº 1, 1986.

Goetschel, Roland. Isaac Abravanel, Conseiller des Princes et Philosophie. Paris: Albain Michel, 1996.

Josephus, Flavius. Antiquities of the Jews. S.L: Veritatis Splendor Publications, 2014.

Kaplan, Lawrence. "Maimonides on the Miraculous Element in Prophecy". The Harvard Theological Review, vol. 70, $\mathrm{n}^{\circ} 3$ e 4.

Kellner, Menachem. "Heresy and the Nature of Faith in Medieval Jewish Philosophy". The Jewish Quarterly Review, vol. 77, No 4, 1987.

Kellner, Menachem. "Isaac Abravanel on the Principles of Judaism". Journal of the American Academy of Religion, vol. 45, nº 4, 1977.

Lawee, Eric. «Isaac Abarbanel's "Stance toward Tradition" The Case of "Ateret zeqenim"». AJS Review, vol. 22, no 2, 1997.

Loewe, James. Isaac Abravanel's Six Lectures. Cambridge: Cambridge University Press, 1937.

Maimonides, Moses. Guide of the Perplexed. Chicago: University of Chicago Press, 1963.

Maimonides, Moses. Thirteen Principles of Faith. Leiden: 1974.

Maimonides, Moses. Book of Letters and Responsa. Jerusalem: 1982.

Maimonides, Moses. Treatise on Logic. Jerusalem: Literary Licensing Reprint, 2001.

Melamed, Avraham. "Isaac Abravanel and Aristotle's Politics: a Drama of Errors". Jewish Political Studies Review, vol. 5, no 3 e 4, 1993.

Mihaly, Eugene. "Isaac Abravanel on the Principles of Faith". Hebrew Union College Annual, vol. 26, 1955. 
Millen, Rochelle. "Isaac Abravanel's Concept of Monarchy". An Interdisciplinary Journal of Jewish Studies, vol. 10, n 9, 1992.

Netahyahu, Benzion. Don Isaac Abravanel: Statesman and Philosopher. New York: Cornell University Press, 1998.

Padua. Marsilius. Defensor Pacis. New York: Columbia University Press, 2001.

Plato. The Collected Dialogues. New Jersey: Princeton University Press, 1999.

Rosenthal, Erwin. "Don Isaac Abravanel, Financier, Stateman and Scholar". Bulletin of John Rylands Library, vol. 21, $\mathrm{n}^{\circ}$ 2, 1937.

Séneca, Lúcio. Cartas a Lucílio. Lisboa: Fundação Calouste Gulbenkian, S.D.

Skalli, Cedric. "Discovering Isaac Abravanel's Humanistic". The Jewish Quarterly Review, vol. 97, $\mathrm{n}^{\circ}$ 1, 2007.

Skalli, Cedric. "Yitsh aq Abravanel's First Edition (Constantinople 1505) Retorical Content and Editorial Background". Hispania Judaica Buletin. The Mandel Institute of Jewish Studies, $n^{\circ}$ 5, 2007.

Strauss, Leo. "Some Remarks on Maimonides Political Science". Interpretation., vol. $18, \mathrm{n}^{\circ} .1,1990$.

Strauss, Leo. What is Political Philosophy? And Other Studies. Chicago: The University of Chicago Press, 1988.

Virgil. Georgics. New York: Bilingual Editions, 2006. 
(Página deixada propositadamente em branco.) 